\title{
Estimation of Heat Transfer Coefficient and Pressure Drop in a Solar Collector Using Fresnel Lenses
}

\author{
Prakash R. Tripathi ${ }^{1}$, Mahesh G. Bhong ${ }^{2}$ \\ ${ }^{1}$ Indira College of Engineering and Management, Savitribai Phule Pune University \\ ${ }^{2}$ Indira College of Engineering and Management, Savitribai Phule Pune University
}

\begin{abstract}
The paper presents the experimental investigation, dimensional analysis and mathematical modeling of the solar collector that uses Fresnel lenses for the heating of air. Two passes have been compared under the forced flow. The heated air can be used for a number of applications including solar drying of fruits and vegetables agricultural crop drying, food processing, dairy industries, seasoning of wood, textile industries and many more. The use of solar energy and its effect on the heat transfer coefficient as well as pressure drop of the collector are analyzed mathematically.
\end{abstract}

Keywords: Fresnel lens, single pass, double pass, hot air

\section{Introduction}

Hot air has been used widely in various engineering applications, be it the automobile sector or aviation sector, hot air is required. Generally hot air is developed by hot air oven, hot air gun etc. which consumes electrical energy. In scientific agriculture, the drying of cereals, grains and other vegetables and fruits without losing their nutritional values have been a practice for storage. Earlier, the drying of various food stuff was carried out by direct drying, later on collectors were developed and the drying of various stuff became easier. Drying applications are generally based on hot air. In present study, an effective trial has been done to produce hot air with the help of solar energy in association with the Fresnel lens. The hot air can be used effectively for solar drying, sterilization, drying of Adhesives / filters / activating emulsions, drying the touchup paints in emergency cases, repairing of broken Water Wiper Bottles, destruction of microorganisms through the use of dry heated air is a gradual phenomenon in medical sciences. So we can finally conclude that the use of dry and heated air is unlimited. Most of the application out of those mentioned uses hot air produced by hot air gun or hot gas oven. In this paper, it is tried to use the solar energy effectively to heat the air. This paper is designed to harness the Fresnel lens and its benefits to make solar technology easily accessible through an up-todate review. The basic water heater models designed by researchers and their dimensional analysis as well as mathematical modeling has been thoroughly reviewed. Based on the similar approach we put the dimensional analysis and mathematical modelling. Calculation for the heat transfer coefficient of the system and the pressure drop calculation is also summarized in the paper.

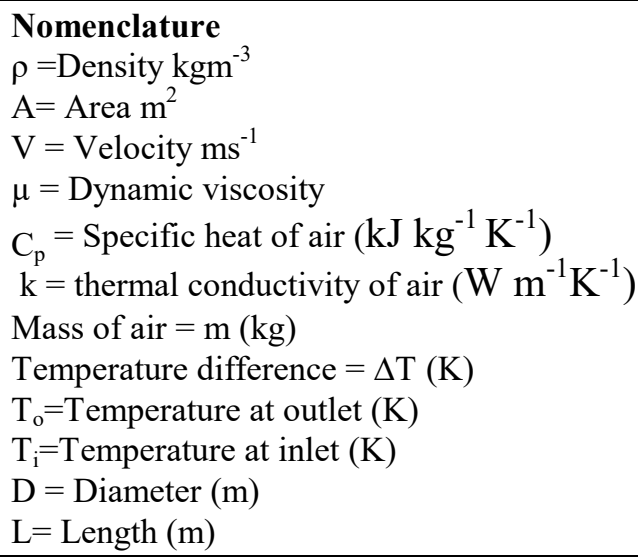

\section{Dimensional Analysis}

Fresnel lenses are seen to be used in a number of applications. The solar drier and other air and water heating devices and there applications are enlisted. For solving this engineering problem, a mathematical technique is preferred which uses of dimensional study. For compressible flow, temperature is considered. Quantities that are expressed in terms of fundamental quantities are called derived quantities. Assuming that the heat transfer coefficient in a fully developed forced convection in a tube is a function of following variables. [1]

Table 1: Parameters to be considered for dimensional analysis

\begin{tabular}{|l|c|c|}
\hline \multicolumn{1}{|c|}{ Variables } & Symbols & Dimensions \\
\hline Fluid Density & $\rho$ & $\mathrm{ML}^{-3}$ \\
\hline Tube Diameter & $\mathrm{D}$ & $\mathrm{L}$ \\
\hline Fluid velocity & $\mathrm{V}$ & $\mathrm{LT}^{-1}$ \\
\hline Fluid viscosity & $\mu$ & $\mathrm{ML}^{-1} \mathrm{~T}^{-1}$ \\
\hline Specific Heat & $\mathrm{c}_{\mathrm{p}}$ & $\mathrm{L}^{2} \mathrm{~T}^{-2} \theta^{-1}$ \\
\hline Thermal conductivity & $\mathrm{K}$ & $\mathrm{MLT}^{-3} \theta^{-1}$ \\
\hline Heat Transfer coefficient & $\mathrm{h}$ & $\mathrm{M} \mathrm{T}^{-3} \theta^{-1}$ \\
\hline
\end{tabular}

Total no of Variables $=\mathrm{m}=7$

No. of Fundamental Dimensions Are M, L, T, $\theta=n=4$ 


\section{International Journal of Science and Research (IJSR) \\ ISSN (Online): 2319-7064}

Index Copernicus Value (2013): 6.14 | Impact Factor (2014): 5.611

No of dimensionless terms $=m-n=7-4=3$

There will be three terms,

$f(\boldsymbol{\pi} \mathbf{\pi} \mathbf{\pi})=0$

Considering the properties as geometrical, flow and fluid we have three repeating variables

$$
\begin{gathered}
\pi_{1}=h^{a 1} \rho^{b 1} D^{c 1} V^{d 1} \mu \\
\pi_{2}=h^{a 2} \rho^{b 2} D^{c 2} V^{d 2} c_{p} \\
\pi_{3}=h^{a 3} \rho^{b 3} D^{c 3} V^{d} k
\end{gathered}
$$

$\pi_{1}$ Term:

$M^{0} \mathrm{~L}^{0} \mathrm{~T}^{0}=\left[M T^{-3} \theta^{-1}\right]^{\alpha 1} \cdot\left[M L^{-3}\right]^{b 1} \cdot[L]^{c 1} \cdot\left[L T^{-1}\right]^{d 1} \cdot\left[M L^{-1} T^{-1}\right]$

Equating the exponents of $\mathrm{M}, \mathrm{L}, \mathrm{T}$ and $\theta$ respectively, we get

For M:

$$
a_{1}+b_{1}+1=0
$$

$b_{1}=-1$

For L:

$$
-3 b_{1}+c_{1}+d_{1}=1
$$$$
c_{1}=-1
$$

For T:

$$
-3 a_{1}-d_{1}=1
$$$$
d_{1}=-1
$$

For $\theta$ :

$$
-a_{1}=0
$$$$
a_{1}=0
$$

$\pi_{1}=h^{0} \rho^{-1} D^{-1} V^{-1} \mu=\frac{\mu}{\rho D V}$

$\pi_{2}$ Term:

$$
\pi_{2}=h^{a 2} \rho^{b 2} D^{c 2} V^{d 2} c_{p}
$$

$M^{0} \mathrm{~L}^{0} \mathrm{~T}^{0}=\left[M T^{-3} \theta^{-1}\right]^{\alpha 2} \cdot\left[M L^{-3}\right]^{b 2} \cdot[L]^{c 2} \cdot\left[L T^{-1}\right]^{d 2} \cdot\left[L^{2} T^{-2} \theta^{-1}\right]$

For M: $\quad a_{2}+b_{2}=0 \quad b_{2}=1$

For L: $\quad-3 a_{2}-d_{2}-2=0 \quad d_{2}=1$

For T: $\quad-a_{2}-1=0 \quad a_{2}=-1$

For $\theta: \quad-3 b_{2}+c_{2}+d_{2}+2=0 \quad c_{2}=0$

$\pi_{2}=h^{-1} \rho^{1} D^{0} V^{1} c_{p}=\frac{\rho V c_{p}}{h}=\frac{\rho V c_{p}}{\frac{k}{D}}=\frac{\rho V c_{p} \mathrm{D}}{k}$

$\pi_{3}$ Term:

$$
\pi_{3}=h^{a 3} \rho^{b 3} D^{c 3} V^{d} k
$$

$M^{0} \mathrm{~L}^{0} \mathrm{~T}^{0}=\left[M T^{-3} \theta^{-1}\right]^{a 3} \cdot\left[M L^{-3}\right]^{b 3} \cdot[L]^{c 3} \cdot\left[L T^{-1}\right]^{d 3} \cdot\left[M L T^{-3} \theta^{-1}\right]$

For M: $\quad a_{3}-3 b_{3}+1=0 \quad b_{3}=0$

For L: $-3 b_{3}+c_{3}+d_{3}+1=0 \quad c_{3}=-1$

For T: $\quad-3 a_{3}-d_{3}-3=0 \quad d_{3}=0$

For $\theta: \quad-a_{3}-1=0 \quad a_{3}=-1$

According to theorem,

$$
\pi_{3}=h^{-1} \rho^{0} D^{-1} V^{0} k=\frac{k}{h D}
$$

$$
\pi_{3}=\phi\left(\pi_{2} \pi_{1}\right)
$$

$$
\begin{aligned}
& \frac{k}{h D}=C\left[\frac{\mu}{\rho V D}\right]^{m^{\prime}}\left[\frac{\rho V C_{p} D}{k}\right]^{n r} \\
& \frac{k}{h D}=C\left[\frac{\mu}{\rho V D}\right]^{n^{\prime}} \quad\left[\frac{\rho V C_{p} D}{k}\right]^{n y} \quad\left[\frac{\mu}{\rho V D}\right]^{m^{\prime}-n^{n}} \\
& \frac{k}{h D}=C\left[\frac{\mu}{\rho V D}\right]^{m^{\prime}}\left[\frac{\rho V C_{p} D}{k}\right]^{n x} \\
& \frac{k}{h D}=C\left[\frac{\mu}{\rho V \mathrm{D}}\right]^{\mathrm{n}^{\prime}} \quad\left[\frac{\rho V C_{\mathrm{p}} \mathrm{D}}{k}\right]^{\mathrm{n}^{\prime}} \quad\left[\frac{\mu}{\rho V \mathrm{D}}\right]^{\mathrm{m}^{\prime}-\mathrm{n}^{\prime}} \\
& \frac{k}{h D}=C\left[\frac{\mu}{\rho V D} \cdot \frac{\rho V C_{p} \mathrm{D}}{k}\right]^{n !}\left[\frac{\mu}{\rho V D}\right]^{m n^{\prime}-n} \\
& \frac{k}{h D}=C\left[\frac{\mu C_{\mathrm{p}}}{k}\right]^{n v}\left[\frac{\mu}{\rho V \mathrm{D}}\right]^{m n^{\prime}-n t}
\end{aligned}
$$

Where $\mathrm{C}, \mathrm{m}$ and $\mathrm{n}$ are constants and are evaluated experimentally,

$$
\mathrm{Nu}=\mathrm{C}(\operatorname{Re})^{\mathrm{m}}(\operatorname{Pr})^{\mathrm{n}}
$$

\section{Experimentation}

To investigate the thermal performance of the solar collector under different conditions in Pune, India, a test system was built as shown in Fig. The collector unit was installed in Indira college (latitude: $18.698^{\circ}$ and longitude: $73.658^{\circ}$ ). The arrangement is very simple and easy to understand. A wooden box is made with a top roof that can open or close with the help of a hinge. As the Fresnel lens used in the experimentation has a focal length of $220 \mathrm{~mm}$ so two pipes of copper are passed exactly with the focus of the lenses used. Manual Tracking is preferred for the arrangement. Thermocouples were inserted at the distance of $4 \mathrm{~cm}$ from the point of major focus. Figure represents the thermocouples in the inserted position. Pt100 thermocouples are used to measure the temperature of the copper surface, meanwhile the inlet and outlet temperature are also recorded. The inlet velocity is measured with the help of hot wire anemometer. Figures depict the single pass and double pass air flow patterns. [2]

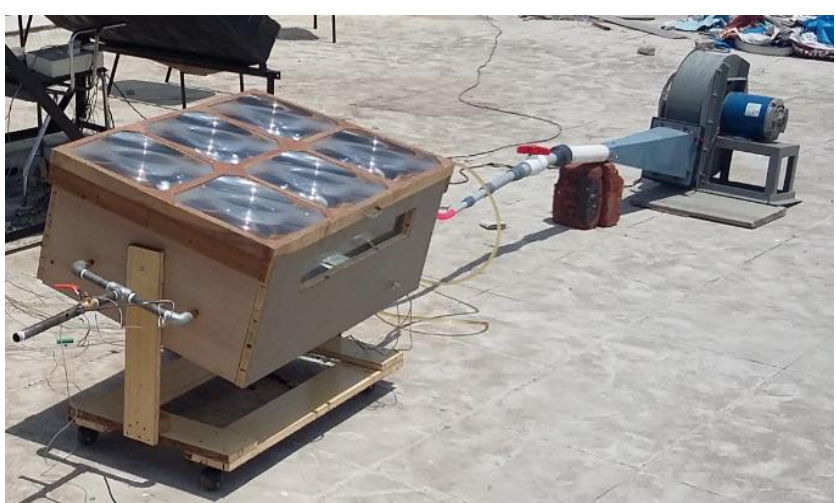

Figure 1: The Solar collector set up for Single and double pass

\section{Mathematical Modelling}

\subsection{Surface collector using Fresnel lens:}

The energy balance on the Fresnel lens considering it a flat surface can be obtained by equating the total heat gained to the total heat loosed by the heat absorber of the solar collector.

Therefore,

$I_{T} A_{c}=Q_{u}+Q_{\text {cond }}+Q_{\text {conv }}+Q_{R}+Q_{\rho}$

$I_{T}=$ rate of total radiation incident on the absorber,s surface $\left(\mathrm{W} / \mathrm{m}^{2}\right)$;

$A_{c}=$ collector area $\left(\mathrm{m}^{2}\right)$;

$Q_{u}=$ rate of useful energy collected by the air $(\mathrm{W})$

$Q_{\text {cond. }}=$ rate of conduction losses from the absorber (W);

$Q_{\text {conv. }}=$ rate of convective losses from the absorber $(\mathrm{W})$;

$Q_{R}=$ rate of long wave re-radiation from the absorber (W);

$Q_{\rho}=$ rate of reflection losses from the absorber (W);

The three heat loss terms $Q_{\text {cond }}, Q_{c o n v}$ and $Q_{R}$ are usually combined into one-term [5].

$Q_{L}=Q_{\text {cond. }}+Q_{\text {conv. }}+Q_{R}$

Continuity equation [6]:

$\frac{\partial u}{\partial x}+\frac{\partial v}{\partial y}+\frac{\partial w}{\partial z}=0$ 


\section{International Journal of Science and Research (IJSR) \\ ISSN (Online): 2319-7064}

Index Copernicus Value (2013): 6.14 | Impact Factor (2014): 5.611

Momentum Equation [6]:

$\rho\left(\frac{\partial u}{\partial t}+u \frac{\partial u}{\partial x}+v \frac{\partial u}{\partial y}+w \frac{\partial u}{\partial z}\right)=-\frac{\partial P}{\partial x}+\mu\left(\frac{\partial^{2} u}{\partial x^{2}}+\frac{\partial^{2} u}{\partial y^{2}}+\frac{\partial^{2} u}{\partial z^{2}}\right)+\rho f_{x}$

$\rho\left(\frac{\partial v}{\partial t}+u \frac{\partial v}{\partial x}+v \frac{\partial v}{\partial y}+w \frac{\partial v}{\partial z}\right)=-\frac{\partial P}{\partial y}+\mu\left(\frac{\partial^{2} v}{\partial x^{2}}+\frac{\partial^{2} v}{\partial y^{2}}+\frac{\partial^{2} v}{\partial z^{2}}\right)+\rho f_{y}$

$\rho\left(\frac{\partial w}{\partial t}+u \frac{\partial w}{\partial x}+v \frac{\partial w}{\partial y}+w \frac{\partial w}{\partial z}\right)=-\frac{\partial P}{\partial z}+\mu\left(\frac{\partial^{2} w}{\partial x^{2}}+\frac{\partial^{2} w}{\partial y^{2}}+\frac{\partial^{2} w}{\partial z^{2}}\right)+\rho f_{z}$

Energy Equation [6]:

$$
\begin{gathered}
\frac{\partial(\rho \theta)}{\partial t}+\nabla \cdot(\rho \theta V)=\rho q+\frac{\partial}{\partial x}\left(k \frac{\partial T}{\partial x}\right)+\frac{\partial}{\partial y}\left(k \frac{\partial T}{\partial y}\right)+\frac{\partial}{\partial z}\left(k \frac{\partial T}{\partial z}\right)- \\
p\left(\frac{\partial u}{\partial x}+\frac{\partial v}{\partial y}+\frac{\partial w}{\partial z}\right)+\lambda\left(\frac{\partial u}{\partial x}+\frac{\partial v}{\partial y}+\frac{\partial w}{\partial z}\right)^{2}+\mu\left[2\left(\frac{\partial u}{\partial x}\right)^{2}\right. \\
+2\left(\frac{\partial v}{\partial y}\right)^{2}+2\left(\frac{\partial w}{\partial z}\right)^{2}+\left(\frac{\partial u}{\partial y}+\frac{\partial v}{\partial x}\right)^{2}+\left(\frac{\partial u}{\partial z}+\frac{\partial w}{\partial x}\right)^{2} \\
\left.+\left(\frac{\partial v}{\partial z}+\frac{\partial w}{\partial y}\right)^{2}\right]
\end{gathered}
$$

5.1

\section{Results and Discussions}

\subsection{Heat Transfer Coefficient}

From Graph 1 it has been found that the heat transfer coefficient of the system increases significantly for both the single as well as double pass. For the single pass, it attains the value of 15.67 at 1000 Reynold number to a maximum of 131.59 at 10000 . Also for the double pass arrangement the minimum value of 15.97 is achieved and the maximum of 132.93 is obtained .Graph depicts the comparison of both the

5.3 passes with the heat transfer coefficients.

\subsection{Estimation of convective heat transfer coefficient:}

\subsection{Pressure Drop}

From Graph 2 it is observed that the increase in the mass flow rates of the air causes increase in the pressure drop. The pressure drop are calculated by using the friction factor. Friction factor are evaluated from the Colebrook equation and Swamee- Jain equation. It can be observed that the Pressure drop for a single pass arrangement is nearly half of the pressure drop in double pass arrangements. At 10000 Reynolds number the significant difference in the pressure drop is observed from $2524 \mathrm{~N} / \mathrm{m}^{2}$ in double pass to the 1208 $\mathrm{N} / \mathrm{m}^{2}$ in the single pass arrangement.

The heat gained by air due to focus on the copper pipe:

$$
\mathrm{Q}=\mathrm{m} \cdot \mathrm{c}_{\mathrm{p}} \cdot \Delta \mathrm{T}
$$

\subsection{Prandtl's Number Calculation}

It is dependent on the viscosity and the thermal conductivity of the fluid.

$$
\operatorname{Pr}=\frac{\mu \oplus p}{k}
$$

\subsection{Nusselt's Number Calculations}

It depends upon whether the flow is laminar or turbulent inside the pipe. We consider the flow to be fully developed as the $\mathrm{L} / \mathrm{D}$ ratio is more than 5 . For the laminar flow when the Reynoldses number is less than $2100,0.5<\operatorname{Pr}<100$

$$
\mathrm{Nu}=\frac{\hbar D}{k}=3.66+\frac{0.0668\left(\frac{D}{L}\right) R \theta_{A Y}}{1+0.04\left[\left(\frac{D}{E}\right) R \theta_{A Y}\right]^{2 / 3}}
$$

For the turbulent flow when the Reynolds se number is more than 4000, and all properties are evaluated at the bulk temperature, length is much greater than diameter and $0.7 \leq$ $\operatorname{Pr} \leq 160$.

$\mathrm{Nu}=0.023(\mathrm{Re})^{0.8}(\mathrm{Pr})^{0.4}$
Convective heat transfer coefficient calculations: $\mathrm{h}=\frac{\mathrm{Nu} \cdot \mathrm{k}}{\mathrm{D}}$

\subsection{Pressure Drop Calculations}

Absolute Roughness Co-efficient for copper is $0.001 \times 10^{3} \mathrm{~m}$.

\section{Comparision of heat transfer coefficient $\mathrm{v} / \mathrm{s}$ Reynolds Number}

300

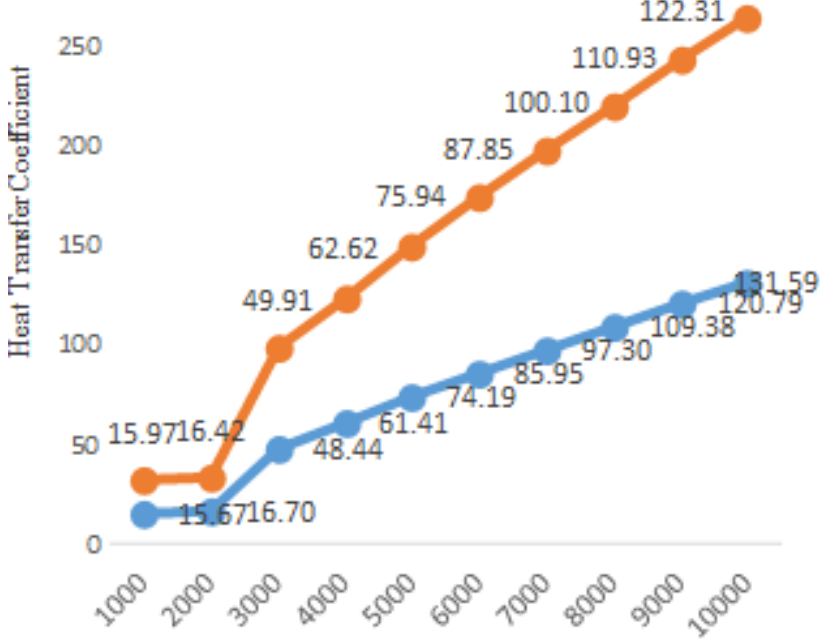

Reynolds No.

$\longrightarrow$ single pass $\longrightarrow$ double pass

Graph 1: Heat Transfer Coefficient variations 


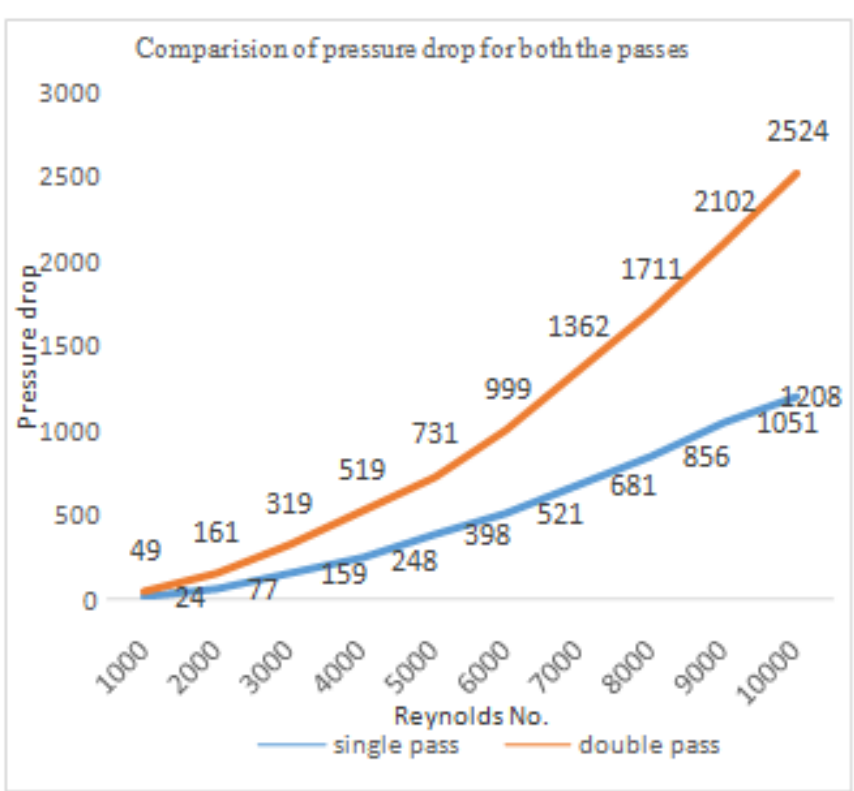

Graph 2: Pressure Drop Comparison for both the passes

\section{Conclusion}

Heat transfer coefficient is maximum for double pass 132.93 $\mathrm{Wm}^{-2} \mathrm{~K}^{-1}$ and for double pass it is $2524 \mathrm{Nm}^{-2}$ which is greater than single pass.

\section{Acknowledgements}

We are very much thankful to BCUD Savitribai Phule Pune University, Pune for funding the research project.

\section{References}

[1] Rajput R.K., "Heat and Mass Transfer", Revised Edition June 2012.

[2] Tripathi P.R., Bhong M.G., "Experimental Analysis of Solar collector with single pass at different mass flow rates", In IJSART-Vol.1, Issue 11, November 2015, pp. 88-91.

[3] Rahman Khatibi, Mohammad Ali Ghorbani, Farzin Salmasi," A study of friction factor formulation in pipes using artificial intelligence techniques and explicit equations." Department of Water Engineering, Faculty of Agriculture, Tabriz University, Tabriz-Iran Consultant Mathematical Modeler, Swindon-United Kingdom,2012

[4] Christos Babajimopoulos, George Terzidis," Accurate Explicit Equations for the Determination of Pipe Diameters." International Journal of Hydraulic Engineering 2013, Department of General and Agricultural Hydraulics and Land Reclamation, Aristotle University of Thessaloniki, Greece 115-120

[5] Promparn Sae-Junga, Tanaporn Krittayanawacha, Phichamon Deedoma, Bundit Limmeechokchaia " $A n$ Experimental Study of Thermo-Syphon Solar Water Heater in Thailand,"Sirindhorn International Institute of Technology, Thammasat University, Thailand.

[6] Anderson, John D., Jr., Fundamentals of Aerodynamics, 2nd Edition McGraw-Hill, New York, 1991. 